\title{
Electroanalytical Study of Aluminum Fluoride Complexation in 2-Propanol-Water Mixtures
}

\author{
Njegomir Radić ${ }^{\dagger}$ and Miljenko PaPA \\ Department of Chemistry, Faculty of Technology, University of Split, 58000 Split, Croatia
}

\begin{abstract}
Theoretical approaches to aluminum-ion determination by two potentiometric methods (potentiometric titration and analyte subtraction potentiometry) are discussed. The computed theoretical titration curves show that the equivalence point is signaled by a sufficiently large change in the potential only in media where aluminum forms a hexafluoride complex; the overall formation constant of this complex is $\beta\left(\mathrm{AlF}_{6}{ }^{3-}\right) \geq 10^{28}$. On the basis of the potentiometric titration and the known subtraction experiments in 2-propanol-water, buffered with acetate buffer (pH 5), the overall conditional constants $\left(\beta^{\prime}\right)$ were calculated. The calculated average $\beta^{\prime}$-values are $10^{31}$ and $10^{33}$, depending on the vol\% of organic solvent, $50 \%$ and $67 \%$. In the mixtures having a vol\% of organic solvent of $50 \%$ or $67 \%$, both methods can be applied for the determination of aluminum, via $\mathrm{AlF}_{6}{ }^{3-}$ complex formation, in the concentration range from $10^{-4}$ to $10^{-3} \mathrm{M}^{\text {. }}$
\end{abstract}

Keywords Potentiometry, fluoride-electrode, aluminum, nonaqueous media

The fluoride ion-selective electrode (FISE) is probably the most widely applied ion-selective electrode used for practical measurements. Fluoride ion is a unique ligand in that it shows an almost pure electrostatic interaction with metal ions in solution. Since the FISE was developed in $1966^{1}$, the formation constants of many metal fluoro complexes in aqueous solution have been determined. However, there are few reports concerning its use for: i) the determination of the formation constant of the complexes in nonaqueous media and ii) the indirect determination of metal ions based on metal fluoride complex formation. Also, the determination of aluminum using sample subtraction alternatively to titration by fluoride has not been investigated in organic solventwater mixtures.

The determination of aluminum using FISE in aqueous solution ${ }^{2-4}$ and organic solvent-water mixtures $^{5,6}$ has been described. Recently, the kineticpotentiometric method has been utilized for determining Al(III) in aqueous acidic solution. ${ }^{7}$ Lingane ${ }^{8,9}$ showed that the response of FISE to fluoride in ethanol-water mixtures was Nernstian, and that the addition of 60 $70 \%$ ethanol was very effective for improving the potentiometric titration curves of $\mathrm{F}^{-}$with $\mathrm{Th}^{4+}, \mathrm{La}^{3+}$ and $\mathrm{Ca}^{2+}$. Bixler and Bond ${ }^{10}$ investigated the behavior of an FISE in methanol, and applied it to study the stabilities of alkaline earth monofluoride complexes in methanol and methanol-water mixtures.

Here, we report on an investigation of the potentiometric determination of aluminum in 2-propanolwater mixtures. The theoretical approach for the determination of aluminum using two potentiometric

\footnotetext{
$\dagger$ To whom correspondence should be addressed.
}

methods (potentiometric titration and analyte subtraction potentiometry) is discussed. The analytical profitability of these methods for the determination of aluminum in 2-propanol-water media is described. Also, on the basis of potentiometric experiments the overall conditional formation constants $\left(\beta^{\prime}\left(\mathrm{AlF}_{6}{ }^{3-}\right)\right)$ in solution with different vol\% of 2-propanol have been calculated.

\section{Theoretical Approaches to the Monitoring of Aluminum-Fluoride Reactions}

\section{Potentiometric titration}

In a slightly acidic solution fluoride species are mainly of the $\mathrm{HF}$ and $\mathrm{F}^{-}$forms. If the solution contains aluminum ions, the following reactions may be considered to be important paths for aluminum-fluoride complex formation:

$$
\begin{aligned}
& \mathrm{Al}^{3+}+i \mathrm{~F}^{-} \rightleftharpoons \mathrm{AlF}_{i}^{(3-i)+} \\
& \mathrm{Al}(\mathrm{OH})_{j^{(3-j)+}}+i \mathrm{~F}^{-}+j \mathrm{H}^{+} \rightleftharpoons \mathrm{AlF}_{i}^{(3-i)+}+j \mathrm{H}_{2} \mathrm{O}, \\
& \mathrm{Al}^{3+}+i \mathrm{HF} \rightleftharpoons \mathrm{AlF}_{i}^{(3-i)+}+i \mathrm{H}^{+},
\end{aligned}
$$

and

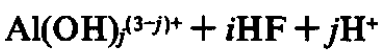

$$
\begin{aligned}
& \rightleftharpoons \mathrm{AlF}_{i}^{(3-i)+}+i \mathrm{H}^{+}+j \mathrm{H}_{2} \mathrm{O} \text {, }
\end{aligned}
$$

where coordinated water in the reactions has been omitted for simplicity.

After the formation of aluminum fluoride complexes 
through one of the above reactions in a solution where $c_{\mathrm{Al}}>\left[\mathrm{AlF}_{i}^{(3-i)+}\right]$, the free fluoride concentration may be calculated from the overall formation constant.

If we accept the formation of an aluminum hexafluoride complex in organic solvent-water mixtures, the fluoride concentration may be expressed by

$$
\left[\mathrm{F}^{-}\right]=\left(\frac{\left[\mathrm{AlF}_{6}{ }^{3-}\right]}{\left\{\left(c_{\mathrm{Al}(\mathrm{III})}-\left[\mathrm{AlF}_{6}{ }^{3-}\right]\right) / k^{\prime}\right\} \beta\left(\mathrm{AlF}_{6}{ }^{3-}\right)}\right)^{1 / 6},
$$

where $k^{\prime}$ denotes a constant part of the expression in a buffered solution,

$$
k^{\prime}=1+\frac{\beta_{1}^{*}}{\left[\mathrm{H}^{+}\right]}+\frac{\beta_{2} *}{\left[\mathrm{H}^{+}\right]^{2}}+\frac{\beta_{3}^{*}}{\left[\mathrm{H}^{+}\right]^{3}} \text {. }
$$

The values of the constants for

$$
\beta_{j}^{*}=\frac{\left[\mathrm{Al}(\mathrm{OH})_{j}^{(3-j)+}\right]}{\left[\mathrm{Al}^{1++}\right]} \times\left[\mathrm{H}^{+}\right]^{j}
$$

$(j=1,2,3)$ were taken from the literature. ${ }^{12}$

The potential of the cell with FISE is given by

$$
E=E^{\prime}-S \log \left[\mathrm{F}^{-}\right],
$$

where $E^{\prime}$ and $S$ denote the conditional standard cell potential and the experimental slope. By combining Eqs. (6) and (5), we obtain

$$
\begin{aligned}
E= & E^{\prime}+\frac{S}{6}\left\{\log \beta\left(\mathrm{AlF}_{6}^{3-}\right)-\log \left(c_{\mathrm{F}} / 6\right)\right. \\
& \left.+\log \left(c_{\mathrm{Al}}-c_{\mathrm{F}} / 6\right)-\log k^{\prime}\right\} .
\end{aligned}
$$

The potential values of the titration curve of aluminum with fluoride may be computed with the aid of theoretical principles using the following equation before the equivalence point:

$$
E=E^{\prime}+\frac{S}{6}\left(\log \beta\left(\mathrm{AlF}_{6}{ }^{3-}\right)-\log k^{\prime}+\log \left(\frac{1-\alpha}{\alpha}\right)\right) .
$$

After the equivalence point,

$$
E=E^{\prime}-S \log \left(\left[\frac{\left(V_{\mathrm{NaF}}-V_{\mathrm{ep}}\right) c_{\mathrm{NaF}}}{V_{\mathrm{T}}}\right] /\left(1+K_{\mathrm{HF}}\left[\mathrm{H}^{+}\right]\right)\right)
$$

is used, where $\alpha, V_{\mathrm{NaF}}, V_{\mathrm{ep}}, V_{\mathrm{T}}$ and $K_{\mathrm{HF}}$ denote the ratio of $\mathrm{AlF}_{6}{ }^{3-}$ to the total aluminum concentration, the added volume of $\mathrm{NaF}$, the volume of the titrant at the equivalence point, the total volume of the reaction solution and the formation constant of HF ( $K_{\mathrm{HF}}$ is $7.93 \times 10^{2}$ in water), respectively. According to the same approach, the potential values of the titration curve of fluoride with aluminum may be calculated by using Eq. (7) after the equivalence point, and the following equation before the equivalence point:

$$
E=E^{\prime}-S \log \left(\left[\frac{n_{\mathrm{F}}-6\left(V_{\mathrm{Al}} c_{\mathrm{Al}}\right)}{V_{\mathrm{T}}}\right] /\left(1+K_{\mathrm{HF}}\left[\mathrm{H}^{+}\right]\right)\right),
$$

where $n$ denotes the quantity of fluoride in the reaction solution.

The theoretical potential changes near to the equivalence point, $V_{\mathrm{ep}} \pm 0.01 V_{\mathrm{ep}}$, have been calculated using Eqs. (8) and (9). The following values were taken into account: $V_{\text {intial }}=50.0 \mathrm{ml}, c_{\mathrm{NaF}}=0.1 \mathrm{M}, V_{\mathrm{ep}}=6.0 \mathrm{ml}$, $k^{\prime}=12.02$ (this value was calculated for an aqueous solution when $\left[\mathrm{H}^{+}\right]=10^{-5} \mathrm{M}$ ) and different values of $\beta\left(\mathrm{AlF}_{6}{ }^{3-}\right)$. According to the computed values, the equivalence point was signaled by a sufficiently large change in the potential only when higher values of the constants, $\beta\left(\mathrm{AlF}_{6}{ }^{3-}\right)>10^{28}$, were used. It is evident that aluminum can not be determined in aqueous media via $\mathrm{AlF}_{6}{ }^{3-}$ complex formation, because its constant in water $\left(1.74 \times 10^{19}\right)$ is too small. ${ }^{12}$ In addition, a simple computer program can be used to trace the theoretical titration curve, and the influence of the $\mathrm{pH}$ on its shape. Although, the greatest change in the potentials was observed when the acidity of the solution was expressed using $\mathrm{pH} 4$, for an additional experimental study of $\mathrm{AlF}_{6}{ }^{3-}$ formation in 2-propanol-water mixtures, the reaction solution was buffered with acetate buffer, pH 5 . In the background of this buffer, both potentiometric methods showed a stable stoichiometric ratio between aluminum and fluoride.

It should be stressed at this point that the organic solvent presumably has an influence on the stability constants of HF and aluminum hydroxide complexes. Since appropriate (2-propanol-water)-values of the constants have not been available in the literature, a conditional, or effective, formation constant for the $\mathrm{AlF}_{6}{ }^{3-}$ complex was calculated in the experimental part of this work. The term "conditional" indicates that this constant applies only under specified conditions. Certainly, although the calculated constants have no thermodynamic meaning, they could have practical applicability.

\section{Known (analyte) subtraction potentiometry}

The change in the potential of the cell with FISE immersed in a known volume $\left(V_{\mathrm{F}}\right)$ of solution containing a known concentration of fluoride $\left(c_{\mathrm{F}}\right)$ depends on volume $\left(V_{\mathrm{Al}}\right)$ of a standard solution (concentration $\left.c_{\mathrm{Al}}\right)$ and the stoichiometric ratio between the aluminum and fluoride.

Before the addition of aluminum the potential is given by

$$
E_{1}=E^{\prime}-S \log \alpha_{\mathrm{F}} c_{\mathrm{F}},
$$

where $\alpha_{\mathrm{F}}=\left[\mathrm{F}^{-}\right] / c_{\mathrm{F}}$ is the ratio of the free-to-total fluoride concentration in a buffered solution. The initial potential is therefore given by

$$
E_{1}=E^{\prime}-S \log \alpha_{\mathrm{F}}-S \operatorname{Slog} c_{\mathrm{F}} .
$$


Added aluminum is assumed to react stoichiometrically with fluoride to give a product to which the electrode does not respond. If $1 \mathrm{~mol}$ of aluminum reacts with $i$ mol of fluoride, the new concentration of fluoride is given by

$$
c_{\mathrm{F}}^{\prime}=\frac{V_{\mathrm{F}} c_{\mathrm{F}}-i\left(V_{\mathrm{Al}} c_{\mathrm{Al}}\right)}{V_{\mathrm{F}}+V_{\mathrm{Al}}}
$$

The potential after the addition of aluminum is

$$
E_{2}=E^{\prime}-S^{\prime} \log \alpha_{\mathrm{F}}^{\prime}-S^{\prime} \log c_{\mathrm{F}}^{\prime}
$$

Assuming that $\alpha_{\mathrm{F}}=\alpha_{\mathrm{F}}^{\prime}$ and $S=S^{\prime}$, we can combine Eqs. (12) and (14) to obtain

$$
\Delta E=E_{2}-E_{1}=S \log c_{\mathrm{F}}-S \log c_{\mathrm{F}}^{\prime}
$$

Substituting for $c_{\text {F }}^{\prime}$ from Eq. (13) and rearranging it we obtain the equation for calculating the stoichiometric ratio between aluminum and fluoride,

$$
i=\frac{c_{\mathrm{F}}}{V_{\mathrm{Al}} c_{\mathrm{Al}}}\left(V_{\mathrm{F}}-\frac{V_{\mathrm{F}}+V_{\mathrm{Al}}}{\operatorname{antilog} \frac{\Delta E}{S}}\right)
$$

Equation (16) can be rearranged to give an expression for calculating an unknown concentration $\left(c_{\mathrm{Al}}\right)$ under experimental conditions where the stoichiometric ratio is known,

$$
c_{\mathrm{Al}}=\frac{c_{\mathrm{F}}\left(V_{\mathrm{F}}-\frac{V_{\mathrm{F}}+V_{\mathrm{Al}}}{\operatorname{antilog} \frac{\Delta E}{S}}\right)}{i V_{\mathrm{Al}}} .
$$

\section{Experimental}

\section{Apparatus and reagents}

Potentiometric measurements were carried out using an Orion 960 Autochemistry System with a doublewalled thermostated reaction vessel maintained at $25 \pm 0.1^{\circ} \mathrm{C}$. The cell potentials were measured with an Orion 94-09 SC FISE versus Orion 90-02 single-junction $\mathrm{Ag} / \mathrm{AgCl}(3 \mathrm{M} \mathrm{HCl})$ reference electrode. The $\mathrm{pH}$ values were measured with an Orion 91-15 glass electrode and an Orion 901 Microprocessor Ionanalyser. During the measurements, the solution was continuously stirred.

All of the chemicals were of analytical-reagent grade, and were used without further purification. All of the solutions were prepared with water doubly distilled in glass. Standard sodium fluoride $(0.1 \mathrm{M})$ was prepared in a polypropylene calibrated flask from dried $(0.1 \mathrm{MPa}$, $110^{\circ} \mathrm{C}$ ) sodium fluoride. A dilute standard fluoride solution was prepared from the stock solution by diluting using a polypropylene flask and pipet.

A standard aluminum solution $(0.1 \mathrm{M})$ was prepared by weighing and dissolving an appropriate amount of aluminum wire (99.99\% aluminum). Then, after $20 \mathrm{ml}$ of conc. $\mathrm{HCl}$ was added to the metal, the beaker was covered and warmed gently. When solution was complete, it was transferred quantitatively to a $250.0 \mathrm{ml}$ volumetric flask and made up to volume with water.

An acetate buffer ( $\mathrm{pH} \mathrm{5)}$ was made by diluting glacial acetic acid $(60.0 \mathrm{ml})$, sodium acetate $(16.3 \mathrm{~g})$, and sodium chloride $(35.0 \mathrm{~g})$ to $1000.0 \mathrm{ml}$. This buffer served as a $\mathrm{pH}$ and ionic-strength adjustor.

\section{Measurement procedure}

Potentiometric titration experiment. First, $5.0 \mathrm{ml}$ of acetate buffer and between 200 and $5000 \mu$ of the chosen aluminum or fluoride solution were pipetted into a thermostated reaction vessel. In this way various amounts of aluminum or fluoride could be transferred to the vessel. Then, water and 2-propanol were added to bring the volume to the same total volume $(30 \mathrm{ml})$ for each experiment, making the vol\% of organic solvent in the range from $33 \%$ to $83 \%$. The standard titrant solution (fluoride or aluminum) was put into a dispenser; then, constant volume increments ( 10 or $100 \mu \mathrm{l})$, the total volume of the titrant solution, and the timed readings (60 s) were selected. After the solution was stirred, the autodispenser and millivolts readings, were switched on. From the collected data the overall conditional formation constant $\left(\beta^{\prime}\left(\mathrm{AlF}_{6}{ }^{3-}\right)\right)$ or the concentration of aluminum in sample solution was calculated.

Subtraction potentiometry. A basic buffered solution with vol\% 2-propanol from $0 \%$ to $83 \%$ was prepared. Then, the standard fluoride solution was added and the potential of the cell with FISE 3 min after each addition recorded. A calibration graph $E$ versus $\mathrm{pF}$ was constructed and the $S$ and $E^{\prime}$ values estimated. A known volume ( $\left.V_{\mathrm{Al}}\right)$ of the standard (or sample) solution was then added and the steady-state potential of the cell recorded. From the collected data the stoichiometric ratio (Eq. (16)), $\beta^{\prime}\left(\mathrm{AlF}_{6}{ }^{3-}\right)(\mathrm{Eq}$. (19)) or the concentration of aluminum in sample solution (Eq. (17)) was calculated.

\section{Results and Discussion}

When the titration of $20.0 \mu \mathrm{mol}$ of aluminum with fluoride was performed in 2-propanol-water mixtures well defined titration curves were obtained, and aluminum hexafluoride was formed at the equivalence point. According to the theoretical consideration, welldefined titration curve with a sharp inflection point can be obtained only if one kind of complex with a sufficiently high overall stability constant is formed during the course of the potentiometric titration.

Titration curves of $20.0 \mu \mathrm{mol}$ of aluminum with $0.1 \mathrm{M}$ fluoride and $500 \mu \mathrm{mol}$ of fluoride with $0.1 \mathrm{M}$ aluminum were carried out in buffered, nonaqueous media, $67 \%$ (v/v) 2-propanol. The shapes of the experimental titration curves are in good agreement with those calculated by means of Eqs. (8), (9), (10) and (7). However, for the 


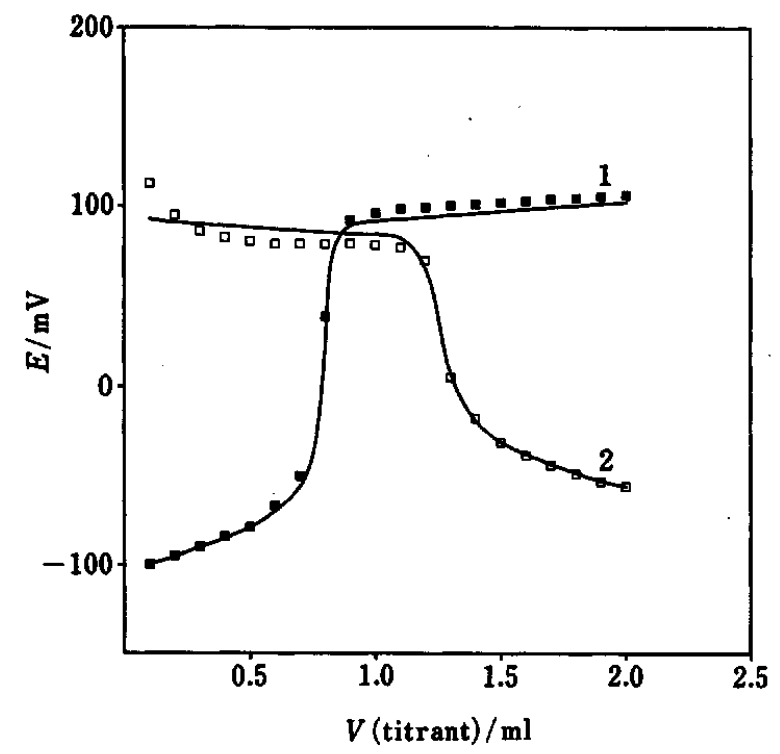

Fig. 1 Titration curves of $500.0 \mu \mathrm{mol}$ of fluoride with $0.1 \mathrm{M}$ aluminum (1- $\square$ ) and $20.0 \mu \mathrm{mol}$ of aluminum with $0.1 \mathrm{M}$ fluoride (2- $\square$ ) in a buffered 2-propanol-water mixtures, $67 \%(v / v)$. The calculated titration curves are traced with lines.

titration of aluminum with fluoride, the experimental potential values before equivalence point are slightly shifted in the negative potential direction. The experimental potential values in this part of titration curve indicate higher concentrations of fluoride than those calculated by using Eq. (7). Since appropriate (organic solvent-water)-values of the constants have not been available in the literature, the potential data of theoretical titration curves have been calculated using aqueous values of $\mathrm{HF}$ and $\mathrm{Al}(\mathrm{OH})_{j}^{\left({ }^{(3-j)+}\right.}$ complexes. The aqueous values of constants of aluminum hydroxide complexes are obviously not suitable for calculating the cell potential before the equivalence point when aluminum ions are in excess.

When one half of the volume at the equivalence point is added, the overall conditional formation constant is related to the measured potential $(E)$ through Eq. (8) in the simplified form,

$$
\log \beta^{\prime}\left(\mathrm{AlF}_{6}{ }^{3-}\right)=\frac{E-E^{\prime}}{S / 6} .
$$

For each potential value after the equivalence point the fluoride concentration was calculated and the plot $E$ versus $\mathrm{pF}$ constructed. The $S$ and $E^{\prime}$ values were estimated for each set of measurements. The values of the formation constant calculated based on the potentiometric titration data of aluminum with fluoride in 2-propanol-water mixtures are shown in Table 1-A. The computed values of the constant increase with increasing vol\% of the organic solvent. It was found that the overall formation constant depended on the initial concentration of aluminum in the experimental; slightly lower values were calculated when the initial
Table 1 Calculated overall conditional formation constants $\left(\beta^{\prime}\left(\mathrm{AlF}_{6}{ }^{3-}\right)\right)$ in 2-propanol-water mixtures based on potentiometric titration experiments (1-A) and known subtraction potentiometry (1-B) 1-A

\begin{tabular}{cccc}
\hline $\begin{array}{c}\text { Analyte } \\
n_{\mathrm{Al}} / \mu \mathrm{mol}\end{array}$ & $\begin{array}{c}\text { Titrant } \\
\text { 0.1 M NaF/ml }\end{array}$ & $\begin{array}{c}\text { 2-Propanol, } \\
\text { vol\% }\end{array}$ & $\log \beta^{\prime}\left(\mathrm{AlF}_{6}{ }^{3-}\right)^{\mathrm{b}}$ \\
\hline 2 & 0.2 & 33 & 28.3 \\
2 & 0.2 & 50 & 30.9 \\
2 & 0.2 & 67 & 33.2 \\
2 & 0.2 & 83 & 36.3 \\
20 & 2 & 33 & 27.7 \\
20 & 2 & 50 & 30.3 \\
20 & 2 & 67 & 32.4 \\
20 & 2 & 83 & 35.8 \\
\hline
\end{tabular}

a. Total volume of titrant added.

b. Calculated by using Eq. (18).

$1-\mathrm{B}$

\begin{tabular}{ccccccc}
$\begin{array}{c}\text { Calibration } \\
\text { range } / \mathrm{pF}\end{array}$ & $\begin{array}{c}n_{\mathrm{F}} / \\
\mu \mathrm{mol}\end{array}$ & $\begin{array}{c}n_{\mathrm{Al}} / \\
\mu \mathrm{mol}\end{array}$ & $c_{\mathrm{Al}}-\left(c_{\mathrm{F}} / 6\right)$ & $\begin{array}{c}\text { 2-Propanol, } \\
c_{\mathrm{F}} / 6\end{array}$ & $\operatorname{vol} \%$ & $\log \beta^{\prime}\left(\mathrm{AlF}_{6}{ }^{3-}\right)^{\mathrm{c}}$ \\
\hline $4.18-2.91$ & 37 & 10 & 0.4 & 50 & 31.4 \\
& & 110 & 16.8 & 50 & 31.4 \\
$4.17-2.91$ & 37 & 10 & 0.4 & 67 & 33.3 \\
& & 110 & 16.8 & 67 & 32.9 \\
\hline
\end{tabular}

c. Calculated by using Eq. (19).

concentration of aluminum was increased.

The observation based on the experiments suggests that the concentration of a complex formed before the equivalence point altered the $S$ and/or $E^{\prime}$ values after the equivalence point, and, hence, decreased the calculated value of the constant.

In order to improve the experimental determination of the overall conditional formation constant of $\mathrm{AlF}_{6}{ }^{3-}$, in another experiment the $S$ and $E^{\prime}$ values were estimated in the first step of experiment. After the addition of aluminum the steady state potential was recorded and used to calculate the constant by using Eq. (7) in the following form:

$$
\beta^{\prime}\left(\mathrm{AlF}_{6}^{3-}\right)=\frac{E-E^{\prime}}{S / 6}+\log \left(c_{\mathrm{F}} / 6\right)-\log \left(c_{\mathrm{Al}}-c_{\mathrm{F}} / 6\right) .
$$

Based on these experiments, the calculated values of the overall conditional formation constant of the $\mathrm{AlF}_{6}{ }^{3-}$ complex in 2-propanol/water media are shown in Table 1-B.

In view of the analytical profitability, it is essential to establish experimental conditions in which a stable and known stoichiometric ratio between aluminum and fluoride exists.

The electrode response to fluoride at constant ionic strength and $\mathrm{pH}$ was carried out in aqueous and 2propanol-water mixtures. The experimental slopes, which slightly decreased with increasing vol\% of organic solvent, were used for a calculation of the stoichiometric ratio between aluminum and fluoride. The results of an 
Table 2 Calculated values of the stoichiometric ratio between aluminum and fluoride $(i)$ by using known subtraction potentiometry

\begin{tabular}{|c|c|c|c|c|c|c|c|c|}
\hline 2-Propanol, vol\% & Calibration range/pF & $S / \mathrm{mV}(\mathrm{pF})^{-1}$ & $E^{\prime} / \mathrm{mV}$ & $r$ & $\frac{n_{\mathrm{F}}}{n_{\mathrm{Al} 1}}$ & $i^{a}$ & $i^{b}$ & $S^{c}$ \\
\hline \multirow[t]{5}{*}{0} & $4.48-2.52$ & 59.1 & -123.3 & 0.9999 & 9.3 & 3.1 & & \\
\hline & & & & & 4.7 & 2.9 & & \\
\hline & & & & & 3.1 & 2.6 & & \\
\hline & & & & & 2.3 & 2.2 & 2.7 & 0.39 \\
\hline & & & & & 1.8 & 1.8 & & \\
\hline \multirow[t]{5}{*}{50} & $4.48-2.52$ & 57.8 & -186.6 & 0.9997 & 6.2 & 5.8 & & \\
\hline & & 57.5 & -185.3 & 0.9998 & 18.2 & 6.1 & & \\
\hline & & & & & 9.3 & 5.9 & & \\
\hline & & & & & 6.2 & 5.9 & 5.9 & 0.02 \\
\hline & & & & & 4.6 & 4.6 & & \\
\hline \multirow[t]{6}{*}{67} & $4.48-2.52$ & 56.5 & -208.8 & 0.9997 & 6.2 & 6.0 & & \\
\hline & & 56.5 & -209.3 & 0.9994 & 9.3 & 6.1 & & \\
\hline & & 56.0 & -207.2 & 0.9996 & 18.2 & 6.3 & & \\
\hline & & & & & 9.3 & 6.2 & & \\
\hline & & & & & 6.2 & 6.0 & 6.1 & 0.02 \\
\hline & & & & & 4.6 & 4.6 & & \\
\hline \multirow[t]{4}{*}{83} & $4.48-2.52$ & 53.7 & -238.5 & 0.9986 & 6.2 & 6.1 & & \\
\hline & & 55.1 & -245.7 & 0.9975 & 18.2 & 6.9 & & \\
\hline & & & & & 9.3 & 6.7 & 6.6 & 0.18 \\
\hline & & & & & 4.6 & 4.6 & & \\
\hline
\end{tabular}

a. Calculated by using Eq. (16). b. Average value. c. Standard deviation.

$i$ determination using known subtraction potentiometry are summarized in Table 2 . In the experimental range of the aluminum concentrations in aqueous media the calculated $i$ values were from 3.1 to 2.2, depending on the added quantity of aluminum. Practically, there is no useful range for the analytical application of any of the considered potentiometric methods. However, when the same experiments were performed in 2-propanolwater mixtures, the calculated values of stoichiometric ratio were very close to six, with a relatively small standard deviation in all of the tested mixtures, except for 2-propanol-water, $83 \%$ (v/v). Also, the potentiometric titration measurements in mixtures with $83 \%$ 2-propanol showed poor reproducibility.

The assumption that aluminum-fluoride complex exists in the $\mathrm{AlF}_{6}{ }^{3-}$ form in solution with fluoride to excess seems to be justified based on the $i$ values obtained in our experiments.

With regard to all of these observations, the utilized electrode can be used with confidence for determining aluminum in 2-propanol-water mixtures with vol\% of an organic solvent from 50 to $67 \%(\mathrm{v} / \mathrm{v})$. In these mixtures, both of the discussed methods (potentiometric titration and analyte subtraction potentiometry), can be applied for the determination of aluminum in the range between $10^{-4}$ and $10^{-3} \mathrm{M}$.

\section{References}

1. M. S. Frant and J. W. Ross, Science [Washington, D.C.], 154, 1553 (1966).

2. B. Jeselskis and M. K. Bandemer, Anal. Chem., 41, 855 (1969).

3. A. Homola and R. O. James, Anal. Chem., 48, 776 (1969).

4. Nj. Radić, Analyst [London], 101, 657 (1976).

5. E. W. Baumann, Anal. Chem., 42, 110 (1970).

6. Nj. Radić, D. Prugo and M. Bralić, J. Electroanal. Chem. Interfacial Electrochem., 248, 87 (1988).

7. Nj. Radić and M. Bralić, Analyst [London], 115, 737 (1990).

8. J. J. Lingane, Anal. Chem., 39, 881 (1967).

9. J. J. Lingane, Anal. Chem., 40, 935 (1968).

10. J. W. Bixler and A. M. Bond, Inorg. Chem., 17, 3684 (1978).

11. J. Kragten, Analyst [London], 99, 43 (1974).

12. J. Inczédy, "Analytical Application of Complex Equilibria", p. 320, Ellis Horwood, Chichester, 1976.

(Received October 11, 1994)

(Accepted February 23, 1995) 